\title{
Encontros com Ubiratan D’Ambrosio: memórias que inspiram políticas de currículo em educação matemática com tecnologias digitais
}

\author{
Marcelo A. Bairral*
}

ORCID iD 0000-0002-5432-9261

Em 12 de maio de 2021, o Presidente de Honra da Sociedade Brasileira de Educação Matemática (SBEM) e um dos grandes educadores matemáticos do mundo, Ubiratan D’Ambrosio, partiu dessa vida aqui conosco. Em 13 de maio de 2021 acessei, aleatoriamente, um editorial do Bolema para me inspirar na elaboração deste, que, com a recomendação que tive, poderia ter uma escrita mais livre e com menos formato dos editoriais convencionais. Curiosamente, o editorial que localizei foi o do Ubiratan ${ }^{1}$. Nele, Ubiratan nos relata memórias de sua relação com Paulo Freire, outro renomado educador e que merece nosso respeito e aplauso. Não tive a honra de conhecer pessoalmente o Paulo Freire, mas fui feliz em ter conhecido o Ubiratan. Não fui orientando nem tive a oportunidade de cursar alguma disciplina ou seminário com Ubiratan, mas palestras assisti várias.

Neste editorial, teço reflexões a partir de conversas com Ubiratan e de leituras de seus escritos, que consigo resgatar em minha memória, procurando circunscrevê-las ao âmbito das tecnologias digitais na formação inicial, inserindo ideias minhas e de alguns autores que considero importantes às discussões curriculares. Parto da premissa de que a aprendizagem deve ser a mola propulsora de políticas de currículo e que diferentes tipos de política interpolam

\footnotetext{
* Doutor em Didática das Ciências Experimentais e da Matemática pela Universidade de Barcelona (UB). Professor Titular da Universidade Federal Rural do Rio de Janeiro (UFRRJ), Rio de Janeiro, Rio de Janeiro, Brasil. E-mail: mbairral@ufrrj.br.

${ }^{1}$ https://www.scielo.br/j/bolema/a/gsy5xZDHXbhhnVw8FGBykCp/?lang=es Acesso: 13 maio 2021.
} 
diferentes tipos de sujeitos da política (BALL; MAGUIRE; BRAUN, 2016).

\section{ICME-10 em Copenhagen ${ }^{2}$}

O International Congress on Mathematical Education (ICME) é um dos maiores congressos dentre os que reúnem matemáticos e educadores matemáticos. $\mathrm{O}$ meu primeiro ICME foi em Copenhagen (Dinamarca, 2004). Eu tinha defendido minha tese em 2002, e minha apresentação no Congresso era sobre o design de ambientes virtuais para a formação de professores de matemática. Em um intervalo do café, graças ao amigo Arthur B. Powell (EUA), fui apresentado ao Ubiratan. Ele, sempre muito gentil e educado! Sentamo-nos e fomos papear. Tenho essa imagem registrada em minha memória fotográfica. Nossa conversa foi sobre a orientação de alunos de graduação e seus temas de interesse. Segundo ele, deveríamos dar mais liberdade aos graduandos na escolha da temática de seu trabalho de conclusão de curso (TCC). Ubiratan era assim, muito atencioso com o outro, sua autonomia, criatividade e potencial. De fato, ele vivia e praticava um mundo de e para a paz, no qual nossa função como professores era educar pela matemática e não com ela, pois ela não deve ser a essência (D’AMBROSIO, 2018).

Sei que a escolha de temas e sua orientação acadêmica é complexa, mas penso que, no Brasil, com os grupos de investigação vinculados à Pós-Graduação, conseguimos constituir coletivos com experiências e formações diferentes e que têm contribuído bastante com a qualidade da pesquisa. Em alguns países, esse trabalho, muitas vezes, é solitário. A comunicação ocorre basicamente com o orientador, e os meios de discussões são apenas congressos.

Duas coincidências interessantes nessa memória com Ubiratan. A primeira palestra que ouvi dele foi no II Congresso Ibero-americano de Educação Matemática (CIBEM), em Blumenau (1994). Como Presidente da SBEM, estou com a responsabilidade, juntamente com pesquisadores da PUC-SP, de organizar o IX CIBEM, em $2022^{3}$. Em julho de 2021, teremos o ICME-14 ocorrendo em Shangai, de forma híbrida. Nele, estou na coordenação de um grupo de trabalho ${ }^{4}$ sobre educação matemática e aprendizagem online. Em tempos pandêmicos, se as pesquisas brasileiras realizadas em educação matemática e educação estivessem sendo acatadas, muitos dos problemas que os professores de matemática enfrentaram, ou ainda estão

\footnotetext{
${ }^{2}$ https://www.mathunion.org/icmi/conferences/icme/past-icmes Acesso: 13 maio 2021.

${ }^{3}$ https://www.pucsp.br/cibem2022. Acesso: 13 maio. 2021.

${ }^{4}$ TSG 49 (Distance learning, e-learning, and blended learning of mathematics): https://www.icme14.org/static/en/news/37.html?v=1623316854280.
} 
enfrentando, seriam menores, mas isso, lamentavelmente, é estratégico.

\section{Currículo como estratégia presente da ação educativa}

Como nos dizia Ubiratan D’Ambrosio, currículo é uma estratégia educativa, portanto, política, pois educar é um ato político, conforme sinalizou, também, Paulo Freire. A escola e os professores produzem política curricular em sua prática (BALL; MAGUIRE; BRAUN, 2016). O currículo pressupõe um relação dinâmica e imbricada entre conteúdos, objetivos e métodos (D’AMBROSIO, 1996). A sua representação no plano cartesiano é muito providencial e interessante na discussão e entendimento desse imbricamento. Utilizo muito essa compreensão relacional em minhas disciplinas na Licenciatura.

Infelizmente, como sinalizam Ball, Maguire e Braun (2016), as escolas britânicas estão cada vez mais focadas nos alunos médios, na tentativa de bajular as tabelas de classificação oficiais. No Brasil, não é diferente! Os processos de ensino e de aprendizagem estão orientados às exigências para aprovação em exames, um conhecimento de curto prazo. Políticas imperativas produzem um profissional técnico, cuja prática é fortemente determinada pelos requisitos de desempenho e entrega, especialmente nas disciplinas de alto risco como a matemática. Esse aumento de padrões (BALL; MAGUIRE; BRAUN, 2016) tem sido um tema constante nos discursos ministeriais e documentos oficiais, e essa cultura de desempenho cria um conjunto de pressões que trabalha de forma descendente, por meio do sistema de educação, desde a Secretaria de Estado até a sala de aula e dentro das casas, criando expectativas de empenho, de entrega, de delivery, conforme sublinham Ball, Maguire e Braun (2016).

Currículo é dinâmico e retroalimentado por (trans)formações e (re)significações efetivamente construídas pelo modo como os implicados produzem significados para a sua leitura do documento prescrito. A sala de aula de matemática deve favorecer uma comunicação pautada em interações, negociações e (re)construções de significados. Portanto, a garantia de êxito de um desenvolvimento curricular não está em determinações legais, embora estas sejam importantes. Porém elas não são determinantes para um sucesso prescrito e objetivamente mapeado (BAIRRAL; ASSIS, 2018).

\section{Currículos: de conteúdos prescritos a processos em potência}

Quando pensamos em currículo, associamos, equivocadamente, somente a conteúdos. Lamentavelmente, com a Base Nacional Comum Curricular (BNCC), o que vemos é uma listagem empobrecida, reducionista, uniformizadora de conteúdos a serem ensinados em 
abrangência nacional. Na formação inicial de professores de matemática, tenho defendido a organização curricular centrada em processos de pensamento (BAIRRAL, 2013). Pensar em processos não prescinde de vislumbrar conteúdos possíveis que podem emergir em determinada situação de causa-efeito.

Ubiratan, frequentemente, enfatizava em suas falas que os conteúdos ficam obsoletos. Os processos de pensamento (BAIRRAL, 2013), não. Os conteúdos aparecerão, mas não são eles que determinarão, exclusivamente, o desenrolar da situação proposta. $\mathrm{O}$ foco do planejador está na imaginação político-pedagógica do(s) processo(s) que almeja detonar com a proposição, e o conteúdo matemático será uma das estratégias para analisar e aprimorar o desenvolvimento do pensamento na atividade matemática constituída, online ou não (BAIRRAL, 2021).

Pensar em currículo centrado em processos ajuda-nos, inclusive, a refletir que educar matematicamente é um ato presente, não um ato meramente futurístico, de preparar para (o próximo ciclo, para o vestibular, para o mercado de trabalho etc.). Processos também podem ser vistos como alternativas para a mudança na organização do espaço físico escolar, nas formas de avaliar o aprendizado, no tempo e na gestão escolar, dentre outros. À medida que a potencialização de processos pode ser concretizada pelas diferentes interações e em ambientes discursivos distintos, os processos podem dar maior autonomia ao professorado (D`AMBROSIO; LOPES, 2015).

Não é uma atividade simples, pois como estudamos matemática em nossa formação inicial, é difícil nos despirmos de uma racionalidade que permeou nossa graduação. Por outro lado, é, também, um desafio exercermos nossa criatividade para colocar em prática o nosso conhecimento matemático para o ensino (BALL; THAMES; PHELPS, 2008).

A máscara 3D que, com a pandemia da COVID-19, passou a fazer parte de nosso corpo, é um exemplo que pode nos inspirar. Em outras épocas, era possível que um estudante concluísse o Ensino Médio sem ter ouvido falar em três dimensões, tridimensional ou 3D. Mesmo alguns adultos, com experiências profissionais diversas, talvez não tenham escutado falar dela. Veja, não temos apenas um novo verbete incluído nas conversações diárias, mas a emergência de uma tecnologia que nos redimensiona. Infelizmente, por uma demanda sanitária e de risco de vida!

Em momentos anteriores da pesquisa sobre a aprendizagem de geometria, estudos sinalizavam que os aspectos tridimensionais deveriam ser o início do ensino e, não, os bidimensionais, como ocorria com as figuras planas. Com a máscara 3D, além das dimensões, outros aspectos relacionais surgem. Por exemplo, os tamanhos do elástico em função do rosto, 
os formatos dos moldes, a adequação do tecido, onde e como fazer as dobras ${ }^{5}$. Como os professores incorporaram essa novidade no seu desenvolvimento curricular? Se você estiver interessado(a) no currículo centrado em processos, reflita sobre possíveis processos de pensamento matemático a serem potencializados nesse exemplo.

Também, esse exemplo é emblemático para o que Ubiratan D’Ambrosio sempre dizia, que a aprendizagem é maior que o ensino. Essa possibilidade de planejamento que coloca a máscara 3D no centro potencializa aprendizagens diversas, em todos os envolvidos, não apenas nos discentes. Quais os docentes que tinham informações sobre os aspectos pontuados no parágrafo anterior? Essa dinâmica insubordina, ainda, práticas nas quais o muito - lista com vários exercícios para serem feitos, por exemplo - pode ser pouco efetivo no aprendizado, e o pouco, falar e registrar sobre um objeto geométrico, por exemplo, pode ser mais enriquecedor (BAIRRAL, 2021a).

\section{Currículos, tecnologias digitais e movimentos emergentes ${ }^{6}$}

A integração de tecnologias (BITTAR, 2011) no ensino e o estudo das diferentes linguagens precisam ser feitos de forma articulada, e não separando a língua materna de outras formas de estar e compreender o mundo, como a Matemática, a História e as Artes. Por sinal, Artes e História eram, sempre, referendadas nas falas de Ubiratan. As tecnologias não podem ser somente associadas - e muitas vezes reduzidas - à inovação ou aos equipamentos. Elas também constituem e podem ser vistas como cultura redimensionada por processos intra e intersubjetivos.

Dentre várias inquietações, dúvidas e transformações que as tecnologias digitais (TD) têm nos proporcionado, algumas têm nos forçados a planejar e criar práticas inovadoras e ambientes formativos, por exemplo:

- A conectividade e o rompimento de fronteiras de espaço físico e de tempo.

- A simultaneidade, a volatilidade e a fluidez na curiosidade e nos modos de criar e descobrir.

\footnotetext{
${ }^{5}$ Veja, por exemplo, o vídeo disponível em https://www.artesanatopassoapassoja.com.br/mascara-3d-de-tecido/. Acesso: 10 maio 2021.

${ }^{6}$ Os agentes que residem em uma escala começam a produzir comportamento em uma dimensão acima deles: "formigas criam colônias; cidadãos criam comunidades; um software simples de reconhecimento de padrões aprende como recomendar novos livros. O movimento das regras de nível baixo para sofisticação do nível mais alto é o que chamamos emergência" (JOHNSON, 2003, p. 14), um sistema "para aprender a partir do nível mais baixo, um sistema onde a macrointeligência e a adaptabilidade advêm do conhecimento local" (JOHNSON, 2003, p. 56).
} 
- A facilidade de localização de informação e de autoaprendizado.

- As interações e as possibilidades de intercâmbios e de colaboração.

- A multimodalidade comunicativa.

- A constituição de redes horizontais, emergentes dos movimentos de base (bottonup) e não direcionados de cima para baixo (top-down), orientados por interesses e perfil dos sujeitos, como indivíduos, mas interconectados.

A mobilidade, que era vista como potente antes da pandemia, nos desafiou. Tivemos que ficar trancados em casa. Nem a dimensão virtual (LEMOS, 2009) da mobilidade nos contemplou. O excesso de deslocamento online nos cansou, além de outras sobrecargas, principalmente, as políticas. Apesar de as TD estarem contribuindo com novas ambiências e arquiteturas sociocognitivas, elas não devem ser vistas como a garantia para a aprendizagem. Aulas com papel e lápis também têm seu valor. Ao longo dos anos, várias pesquisas em educação matemática já mostraram que cada recurso (didático, TD etc.) contribui de forma cognitiva e comunicativamente diferente no aprendizado. É necessário assumir que a apropriação dos meios tecnológicos deve ser constantemente problematizada. Uma vez que nossos alunos estão naturalmente motivados para o uso da informática, o desafio será mantêlos seduzidos para interagir e aprender, em um processo crítico de apropriação.

\section{Currículo com tecnologias na BNC-Formação: Uso ou apropriação?}

Vivemos, continuamente, inovando e os currículos precisam acompanhar e promover mudanças. Ninguém duvida que as tecnologias digitais móveis podem contribuir com mudanças qualitativas nas intervenções docentes, no currículo e no aprendizado (BAIRRAL; HENRIQUE, 2021). Todavia, não será apenas inserindo as TD nos currículos que a qualidade da formação estará garantida.

A Resolução ${ }^{7}$ que define as Diretrizes Curriculares Nacionais para a Formação Inicial em nível Superior de Professores para a Educação Básica e institui a Base Nacional Comum para a Formação Inicial de Professores da Educação Básica (BNC-Formação) deve ser implementada em todas as modalidades dos cursos e programas destinados à formação docente (BRASIL, 2020). Conforme anunciado em seus artigos $3^{\circ}$ e $4^{\circ}$, com base nos mesmos princípios das competências gerais estabelecidas pela BNCC, são explicitadas competências específicas que se referem a três dimensões fundamentais, as quais, de modo interdependente e sem

\footnotetext{
${ }^{7}$ Resolução CNE/CP 2/2019. Diário Oficial da União, Brasília, 15 de abril de 2020, Seção 1, p. 46-49.
} 
hierarquia, se integram e se complementam na ação docente. São elas: conhecimento profissional, prática profissional e engajamento profissional.

Fazendo uma busca pelos termos tecno e digital foram encontradas doze ocorrências, sendo onze delas competências (gerais ou específicas). A partir dessas onze farei uma leitura singela, com olhos voltados para as tecnologias digitais na formação inicial de professores de matemática, sobretudo, no seu processo de apropriação e desenvolvimento humano a partir das competências elencadas. Trata-se de uma interpretação provocativa, e não refletirei sobre outras que, igualmente, me instigam, por exemplo, a diferença entre competência e habilidade, sobre aprendizagens essenciais, sobre objetos de conhecimento, sobre o imbricamento das dimensões especificas, sobre sistemas de monitoramento, registro e acompanhamento das aprendizagens. Vejamos o Quadro 1.

\section{COMPETÊNCIAS GERAIS DOCENTES}

2. Pesquisar, investigar, refletir, realizar a análise crítica, $\underline{\mathrm{usar}}^{\mathbf{8}}$ a criatividade e buscar soluções tecnológicas para selecionar, organizar e planejar práticas pedagógicas desafiadoras, coerentes esignificativas.

4. Utilizar diferentes linguagens - verbal, corporal, visual, sonora e digital - para se expressar e fazer com que o estudante amplie seu modelo de expressão ao partilhar informações, experiências, ideias e sentimentos em diferentes contextos, produzindo sentidos que levem ao entendimento mútuo.

5. Compreender, utilizar e criar tecnologias digitais de informação e comunicação de forma crítica, significativa, reflexiva e ética nas diversas práticas docentes, como recurso pedagógico e como ferramenta de formação, para comunicar, acessar e disseminar informações, produzir conhecimentos, resolver problemas e potencializar as aprendizagens.

Quadro 1: Captura dos verbetes tecno e digital nas dez competências gerais

Fonte: elaboração própria com base na CNE/CP n.2/2019 (BRASIL, 2020)

Enquanto as três competências gerais encontradas (de um total de dez) sinalizarem ações mais potentes (pesquisar, refletir, compreender, criar) quanto ao desenvolvimento do conteúdo do conhecimento profissional docente com as habilidades (ou competências?), nas dimensões específicas temos outros problemas. Elas são complexas e simplificadoras (1.3.3), evasivas (2.1.5), de aparente controle (2.3.5) ou restritivas (2.4.5). Na verdade, há um elenco maior de competências limitadoras $(1.3 .3,2.1 .5,2.3 .5,3.2 .3,3.2 .4,3.3 .2,3.4 .3)$ e cujas implicações tendem a colocar a objetividade tecnológica (a tecnologia material per si e suas promessas de inovações, vantagens, encantamentos e consumos como protagonista de um processo que deve se voltar ao desenvolvimento humano e suas formas de existência com tecnologias. Ou seja, a tecnologia não deve ser o fim em si mesma, ela não pode ser a essência. O Quadro 2 apresenta as habilidades em cada competência.

\footnotetext{
${ }^{8}$ As palavras localizadas pela busca estão em negrito e as sublinhadas são as que orientam a ação de usar e seus sinônimos.
} 


\begin{tabular}{|c|c|}
\hline \multicolumn{2}{|c|}{ 1. DIMENSÃO DO CONHECIMENTO PROFISSIONAL } \\
\hline Competências Específicas & Habilidades (21 ao todo) \\
\hline $\begin{array}{l}\text { 1.1 Dominar os objetos de } \\
\text { conhecimento e saber como } \\
\text { ensiná-los }\end{array}$ & (1.1.1 a 1.1.7) Não identificado \\
\hline $\begin{array}{l}\text { 1.2 Demonstrar conhecimento } \\
\text { sobre os estudantes e como eles } \\
\text { aprendem }\end{array}$ & (1.2.1 a 1.2.6) Não identificado \\
\hline 1.3 Reconhecer os contextos & $\begin{array}{l}\text { (1.3.1 a 1.3.4) 1.3.3 Conhecer o desenvolvimento tecnológico mundial, } \\
\text { conectando-o aos objetos de conhecimento, além de fazer uso crítico } \\
\text { de recursos e informações. }\end{array}$ \\
\hline $\begin{array}{l}\text { 1.4 Conhecer a estrutura e a } \\
\text { governança dos sistemas } \\
\text { educacionais }\end{array}$ & (1.4.1 a 1.4.4) Não identificado \\
\hline \multicolumn{2}{|c|}{ 2. DIMENSÃO DA PRÁTICA PROFISSIONAL } \\
\hline Competências Específicas & Habilidades (22 ao todo) \\
\hline $\begin{array}{l}\text { 2.1 Planejar ações de ensino que } \\
\text { resultem em efetivas aprendizagens }\end{array}$ & $\begin{array}{l}\text { (2.1.1 a 2.1.7) } 2.1 .5 \text { Realizar a curadoria educacional, utilizar as } \\
\text { tecnologias digitais, os conteúdos virtuais e outros recursos } \\
\text { tecnológicos e incorporá-los à prática pedagógica, para potencializar e } \\
\text { transformar as experiências de aprendizagem dos estudantes e } \\
\text { estimular uma atitude investigativa. }\end{array}$ \\
\hline $\begin{array}{l}2.2 \text { Criar e saber gerir ambientes de } \\
\text { aprendizagem }\end{array}$ & (2.2.1 a 2.2.3) Não identificado \\
\hline $\begin{array}{l}2.3 \text { Avaliar o desenvolvimento do } \\
\text { educando, a aprendizagem e o } \\
\text { ensino }\end{array}$ & $\begin{array}{l}\text { (2.3.1 a 2.3.6) 2.3.5 Fazer uso de sistemas de monitoramento, registro e } \\
\text { acompanhamento das aprendizagens utilizando os recursos } \\
\text { tecnológicos disponíveis. }\end{array}$ \\
\hline $\begin{array}{l}\text { 2.4 Conduzir as práticas } \\
\text { pedagógicas dos objetos do } \\
\text { conhecimento, dascompetências } \\
\text { e habilidades }\end{array}$ & $\begin{array}{l}\text { (2.4.1 a 2.4.6) 2.4.5 Usar as tecnologias apropriadas nas práticas de } \\
\text { ensino. }\end{array}$ \\
\hline \multicolumn{2}{|c|}{ 3. DIMENSÃO DO ENGAJAMENTO PROFISSIONAL } \\
\hline Competências Específicas & Habilidades (19 ao todo) \\
\hline $\begin{array}{l}\text { 3.1 Comprometer-se com o próprio } \\
\text { desenvolvimentoprofissional }\end{array}$ & (3.1.1 a 3.1.5) Não identificado \\
\hline $\begin{array}{l}\text { 3.2 Comprometer-se com a } \\
\text { aprendizagem dos estudantes e } \\
\text { colocar em prática o princípio de } \\
\text { que todos são capazes de aprender }\end{array}$ & $\begin{array}{l}\text { (3.2.1 a 3.2.5) 3.2.3 Conhecer, entender e dar valor positivo às } \\
\text { diferentes identidades e necessidades dos estudantes, bem como ser } \\
\text { capaz de utilizar os recursos tecnológicos como recursos pedagógicos } \\
\text { para garantir a inclusão, o desenvolvimento das competências da } \\
\text { BNCC e as aprendizagens dos objetos de conhecimento para todos os } \\
\text { estudantes. } \\
\text { 3.2.4 Atentar nas diferentes formas de violência física e simbólica, bem } \\
\text { como nas discriminações étnico-raciais praticadas nas escolas e nos } \\
\text { ambientes digitais, além de promover o uso ético, seguro e responsável } \\
\text { das tecnologias digitais. }\end{array}$ \\
\hline $\begin{array}{l}\text { 3.3 Participar do Projeto } \\
\text { Pedagógico da escola e da } \\
\text { construção de valoresdemocráticos }\end{array}$ & $\begin{array}{l}\text { (3.3.1 a 3.3.4) 3.3.2 Trabalhar coletivamente, participar das } \\
\text { comunidades de aprendizagem e incentivar o uso dos recursos } \\
\text { tecnológicos para compartilhamento das experiências profissionais. }\end{array}$ \\
\hline $\begin{array}{l}\text { 3.4 Engajar-se, profissionalmente, } \\
\text { com asfamílias e com a } \\
\text { comunidade }\end{array}$ & $\begin{array}{l}\text { (3.4.1 a 3.4.5) 3.4.3 Saber comunicar-se com todos os interlocutores: } \\
\text { colegas, pais, famílias e comunidade, utilizando os diferentes recursos, } \\
\text { inclusive as tecnologias da informação e comunicação. }\end{array}$ \\
\hline
\end{tabular}

Quadro 2 - Captura dos verbetes tecno e digital nas três dimensões Fonte: elaboração própria com base na CNE/CP n.2/2019 (BRASIL, 2020) 
Estudos sobre tecnologia educacional sublinham a diferença entre usar (e seus sinônimos sublinhados nos Quadros) e apropriar-se, tornar próprio para si ${ }^{9}$. Trata-se de um documento que produz discursos de política e os sujeitos são capturados por esses discursos (BALL; MAGUIRE; BRAUN, 2016). Portanto, as palavras não são entes isolados, elas constituem ações que reverberam esses discursos em sujeitos diversos da política.

A política deve deixar de ser uma determinação - em primeira ou em última instância da economia para assumir primazia na constituição do social. A economia é, ela mesma, política, depende de decisões políticas. Os discursos instituídos da política - linguagem, práticas, instituições - são entendidos como formas de ordenar dimensões, mas, também, como capazes de subverter e refundar o social de outras maneiras, reconhecidamente antagônicas e conflituosas. Política remete muito mais a conflito do que a consenso, muito mais a produção de sentidos e movimentos diferentes do que a definição de universalismos categóricos e de regras de organização (LOPES, 2015).

Como educadores matemáticos, não podemos reduzir nossos contextos formativos à mera realização de tarefas procedimentais com as TD, com o objetivo de facilitar o aprendizado ou minimizar dificuldades conceituais dos envolvidos. Os programas de formação docente devem colocar os futuros professores em constante reflexão crítica sobre o que eles próprios aprendem (ou não), quando estão imersos em contextos mediados por tecnologias e impregnados dela.

Está em nossas mãos, como formadores, como pesquisadores, continuar clamando por mudanças qualitativas no processo educativo, porque há muita coisa na contramão, na destruição de conquistas e de garantias, como, por exemplo, a Base Nacional Comum Curricular (BNCC) ou a nova Reforma do Ensino Médio. Currículo não é uma ação homogeneizadora, comum ou, muito menos, um conjunto - mínimo - de competências, previamente determinadas por agentes externos às instituições educativas (BAIRRAL, 2021b) . Como nos diz Lopes (2015, p. 448) "a política é da ordem do acontecimento, remete a uma ética que não pode ser definida a priori e de uma vez por todas".

Como idealizadores e implementadores de políticas públicas, temos que defender a rápida aquisição, pelos futuros professores, de recursos computacionais (incluindo pacote de

\footnotetext{
${ }^{9}$ Citando Serge Proulx, Cardon (2005, p. 23), consideram-se quatro condições para a apropriação social de uma tecnologia: 1) o domínio técnico e cognitivo do artefato, 2) a integração significativa do objeto técnico na prática cotidiana do usuário, 3) o uso repetido dessa tecnologia, que abre possibilidades de criação (ações que gerem novidades na prática social), 4) finalmente, em nível mais propriamente coletivo, a apropriação social supõe que os usuários sejam adequadamente representados no estabelecimento de políticas públicas e, ao mesmo tempo, levados em consideração nos processos de inovação.
} 
dados robustos) que atendam às demandas contemporâneas de sua profissão. Da mesma forma, devemos investir no equipamento e na conexão dos estabelecimentos de ensino e na formação (inicial e continuada) de professores para usar a tecnologia informática. No entanto, nesse processo de aquisição de equipamentos e de estabelecimento de conexões em banda larga, deve estar continuamente presente a dimensão do letramento (WARSCHAUER, 2006).

Não se pode confundir Internet e conectividade via computadores com redes sociais ou acesso via smartphones. A pandemia do COVID-19 acentuou nossas desigualdades sociais e educacionais. Precisamos de investimentos em plataformas públicas para a constituição de ambientes de aprendizagens diversos. Como disse em Bairral (2020), políticas como Um computador por aluno, conhecida como $\mathrm{UCA}^{10}$, o Plano Nacional do Livro Didático (PNLD) com a inserção do livro digital, a Rede Internacional Virtual de Educação (RIVED) ${ }^{11}$ e o Sistema Universidade Aberta do Brasil $(\mathrm{UAB})^{12}$ são iniciativas que, se não tivessem sido extintas (UCA, RIVED) ou deixadas em segundo plano, poderiam ter minimizado os problemas que passamos na Pandemia da COVID-19 com a carência de material didático online oficial que considerasse nossas diferenças regionais e que apoiasse, pedagogicamente, os professores. Foi preciso que cada rede oficial (municipal ou estadual) desenvolvesse, às pressas, seu material que, além de conter várias inadequações e incorreções foram, certamente, mais custosos.

Se tivéssemos políticas que subsidiassem continuamente os profissionais para dinamizarem o seu currículo em sintonia com propósitos da educação online poderia ter sido menos sofrido para docentes, familiares e demais envolvidos no processo educativo. Temos que estar sempre alertas com os oportunismos e os mercenários da educação. Cuidado com ensino híbrido e a home schooling!

O que deve fazer parte da Educação Básica é a educação online (com suas múltiplas formas de linguagem e comunicação, com uso variado de recursos e produção de conteúdos etc.) todas com desenhos didáticos adequados e sustentadas em um currículo com planejamento coletivo, responsável e comprometido dos educadores, com formação adequada para tal, não por sujeitos externos ao cenário educacional, os profissionais técnicos idealizados na BNCFormação.

\footnotetext{
${ }^{10}$ Um Computador por Aluno.

${ }^{11} \mathrm{http}: / /$ rived.mec.gov.br/ Acesso: 4 jun. 2018.

12 http://uab.capes.gov.br/ Acesso: 2 jul. 2020.
} 


\section{0 currículo e a defesa da ética}

Em que essa conversa e reflexão tem a ver com o encontro com o Ubiratan, em Copenhagen? No fato de essas políticas imperativas de currículos (BALL; MAGUIRE; BRAUN, 2016), como o caso da BNCC e da BNC-F, não incentivarem a autonomia dos sujeitos, mas, sim, um padrão, uma performatividade e um pressuposto de consensualidade (LOPES, 2015) e de entrega (BALL; MAGUIRE; BRAUN, 2016).

O pressuposto da universalidade, para Ubiratan, está na educação universal para o pleno desenvolvimento da criatividade desinibida, que, ao mesmo tempo que preserva a diversidade, elimina as inequidades. Em políticas imperativas de currículo, os julgamentos e desconfortos éticos são colocados de lado (BALL; MAGUIRE; BRAUN, 2016). Por exemplo, um professor sabe que seu aluno tem alguma dificuldade. A sua nota em determinado exame externo não evidenciou isso, mas o docente não explicita desconforto ou discute isso em sua unidade escolar. Ubiratan, em sua "ética da diversidade" clama o "respeito pelo outro com todas as suas diferenças, a solidariedade com o outro na satisfação de necessidades de sobrevivência e de transcendência, e a cooperação com o outro na preservação do patrimônio natural e cultural comum" (D’AMBROSIO, 1996, p. 121, itálicos do original). Sentiremos muita saudade, Ubiratan, mas sabemos que você está em um bom lugar!

\section{Referências}

BAIRRAL, M. As TIC e a licenciatura em matemática: Em defesa de um currículo focado em processos. Jornal Internacional de Estudos em Educação Matemática,São Paulo, v. 6, n. 1, p. 1$20,2013$.

BAIRRAL, M. A. (Ed.). Ambiências e redes online: interações para ensino, pesquisa e formação docente. São Paulo: Editora Livraria da Física, 2020.

BAIRRAL, M. A. Escrevendo sobre cubo e estacionando bicicletas: tarefas visando à promoção de práticas insubordinadas em educação matemática. Revista @mbienteeducação, São Paulo, v. 14, n. 1, p. 244-268, 2021a. DOI: 10.26843/ae19828632v14n12021p244a268.

BAIRRAL, M. A. Tecnologias, neurocognição e aprendizagem matemática. Campinas: Mercado das Letras, 2021b.

BAIRRAL, M. A.; ASSIS, A. R. D. Educação Matemática e Currículo: Processos para além da Educação Básica. In: SARTÓRIO, L. A. V.; LINO, L. A.; SOUZA, N. M. P. de (Eds.). Política Educacional e dilemas do ensino em tempo de crise: juventude, currículo, reformas do ensino e formação de professores. São Paulo: Editora Livraria da Física, 2018. p. 187-208.

BAIRRAL, M. A.; HENRIQUE, M. P. (Eds.). Smartphones com toques da Educação Matemática: Mãos que pensam, inovam, ensinam, aprendem e pesquisam. Curitiba: CRV, 2021. 
BALL, D. L.; THAMES, M. H.; PHELPS, G. Content knowledge for teaching: what makes it special? Journal of Teacher Education, Edimburgo, v. 59, n. 5, p. 389-407, 2008. DOI:

$10.1177 / 0022487108324554$.

BALL, S. J.; MAGUIRE, M.; BRAUN, A. Como as escolas fazem as políticas: atuação em escolas secundárias. Ponta Grossa: Editora UEPG, 2016.

BITTAR, M. A abordagem instrumental para o estudo da integração da tecnologia na prática pedagógica do professor de matemática. Educar em Revista, Curitiba, n. 1 (Número Especial Dossiê Psicologia da Educação Matemática), p. 157-171, 2011.

BRASIL. Ministério da Educação. Conselho Nacional de Educação. Conselho Pleno. Resolução CNE/CP n. 2, de 20 de dezembro de 2020. Diário Oficial da União: seção 1, Brasília, p. 46-49, 15 abr. 2020.

CARDON, D. A invenção pelo uso. In: AMBROSI, A.; PEUGEOT, V.; PIMIENTA, D. (Eds.). Desafios de Palavras: Enfoques Multiculturais sobre as Sociedades da Informação. Caen: C \& F Éditions, 2005. p. 21-32.

D’AMBROSIO, U. Educação Matemática: da teoria à prática. Campinas: Papirus, 1996.

D'AMBROSIO, U. To Think in a New Way in Mathematics Education. In: RIBEIRO, L. H. A. J.; BORBA, R. E. de S. R.; FERNANDES, S. H. A. A. (Eds.). Mathematics Education in Brazil: Panorama of Current Research Cham: Springer, 2018. p. 1 -19.

D’AMBROSIO, B.; LOPES, C. E. Insubordinação Criativa: um convite à reinvenção do educador matemático. Bolema, Rio Claro, v. 29, n. 51, p. 1-17, 2015.

JOHNSON, S. Emergência: a vida integrada de formigas, cérebros, cidades e softwares.. Rio de Janeiro: Jorge Zahar Ed, 2003.

LEMOS, A. Cultura da mobilidade. Famecos, Porto Alegre, v. 1, n. 40, p. 28-35, 2009.

LOPES, A. C. Por um currículo sem fundamentos. Linhas Críticas, Brasília, v. 21, n. 45, p. 445-466, 2015.

WARSCHAUER, M. Tecnologia e inclusão social: a exclusão em debate. São Paulo: SENAC São Paulo, 2006. 